\title{
Antioxidant activities of Juniperus foetidissima essential oils against several oxidative systems
}

\author{
S. A. Emami, ${ }^{, 1}$ S. Asgary, ${ }^{2}$ G. A. Naderi, ${ }^{2}$ M. R. Shams Ardekani, ${ }^{3}$ \\ T. Kasher, ${ }^{4}$ S. Aslani, ${ }^{4}$ A. Airin, ${ }^{4}$ A. Sahebkar ${ }^{5}$
}

${ }^{I}$ Department of Pharmacognosy, School of Pharmacy, Mashhad University of Medical Sciences, Iran,

${ }^{2}$ Isfahan Cardiovascular Research Center, Isfahan University of Medical Sciences, Iran,

${ }^{3}$ Department of Pharmacognosy, School of Pharmacy, Tehran University of Medical Sciences, Iran,

${ }^{4}$ School of Pharmacy, Isfahan University of Medical Sciences, Iran,

${ }^{5}$ Biotechnology Research Center and School of Pharmacy, Mashhad University of Medical Sciences, Iran.

Revista Brasileira de Farmacognosia Brazilian Journal of Pharmacognosy 21(4): 627-634, Jul./Aug. 2011

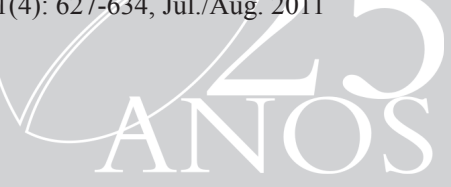

\begin{abstract}
The present study aimed to evaluate the antioxidant activity of essential oils obtained from branchlets of male and female trees as well as fruits of Juniperus foetidissima Willd., Cupressaceae, from Iran. For this purpose, essential oils of $J$. foetidissima were phytochemically analyzed and different concentrations of them were tested in five oxidative systems: 1) low-density lipoprotein oxidation; 2) linoleic acid peroxidation; 3) red blood cell hemolysis; 4) hemoglobin glycation; and 5) insulin glycation assays. In all employed systems, antioxidant effects were observed from the three tested oils though in varying degrees. The most promising activities of the oils were observed against hemoglobin and insulin glycation. Antioxidant activities of the oils did not appear to be dose-dependent. In addition, no consistent superiority in antioxidant effects was observed from a single oil in different assays. In view of the current results, $J$. foetidissima branchlet and fruit oils could be regarded as effective natural products with anti-glycation activity.
\end{abstract}

Article

Received 10 Jan 2010

Accepted 12 Mar 2011

Available online 8 Jul 2011

ISSN 0102-695X

doi: $10.1590 / \mathrm{S} 0102-695 \mathrm{X} 2011005000120$

\section{Introduction}

Oxidative stress is defined as an imbalance between the generation of pro-oxidant species and the ability of organism's antioxidant defense systems to detoxify these species. Thus far, the role of oxidative stress has been documented in the pathophysiology of numerous disorders. Cardio- and cerebrovascular diseases as well as diabetes mellitus are important examples of these disorders, whose prevalence are reaching near epidemic levels and thus regarded as public health concerns (Chrissobolis \& Faraci, 2008; Lakshmi et al., 2009; Giacco \& Brownlee, 2010).

The most important types of pro-oxidant species responsible for the development of oxidative stress are reactive oxygen species (ROS). ROS are highly reactive molecules which can react with different types of biomolecules and cause tissue injury. Among the main targets of ROS are lipids, in particular polyunsaturated fatty acids that are present in biological membranes (Beal et al., 1997). Lipid peroxidation could lead to the loss of structure and function of membranes and generation of cytotoxic and mutagenic end products which can spread the oxidative reactions and cause further damage (Esterbauer et al., 1991; Green \& Reed, 1998; Nigam \& Schewe, 2000). An example of such a harmful lipid peroxidation reaction is the oxidation of LDL which is regarded as the underlying mechanism for the development of atherosclerosis (Esterbauer et al., 1992; Ylä-Herttuala et al., 2000). Another consequence of oxidative stress is the acceleration of non-enzymatic glycation of proteins resulting in the formation of advanced glycation end products (AGE) (Wautier \& Guillausseau, 2001). AGE adversely affect the function of proteins and have been clearly demonstrated to play an important role in the development of chronic micro- and macrovascular complications of diabetes mellitus such as diabetic retinopathy, nephropathy, neuropathy and macroangiopathy (Jakus et al., 1998; Dickinson et al., 2002; Krajcovicová-Kudlácková et al., 2002). Besides, AGE have been shown to increase the susceptibility of LDL to oxidation and could thereby trigger the process of atherosclerosis (Kawamura et al., 1994; Napoli et al., 1997; Liguori et al., 2001). 
With respect to the role of oxidative stress in the pathophysiology of human diseases, antioxidant therapy has been proposed as an effective approach for the prevention and treatment of multiple disorders. Moreover, there has been a surge of interest to find effective antioxidants from natural sources.

Juniperus foetidissima Willd., Cupressaceae, is a tree $5-15 \mathrm{~m}$ high and branched to the ground with crown slender conical and short branchlets. Its fruits are solitary, but numerous, on short branches, globose, 6-12 mm thick, red-brown to black, pruinose and usually with 1-2 seeds. This plant is found in mountains of Greece, Albania, former Yugoslavia and Asia Minor to Transcaucasus. The Persian name of this species is “Arduj” (Riedl, 1968; Sabeti, 1975; Assadi, 1998).

Investigations regarding the biological activities of this plant have been few, with only a few reports on the antifungal, antimicrobial, cytotoxic and preliminary antioxidant effects (Balaban et al., 2003; Emami et al., 2007; Sadeghi-aliabadi et al., 2009; Asili et al., 2010). In addition, some antioxidant effects have been reported from the essential oil of the plant using preliminary tests (Emami et al., 2009). The present study, aimed to evaluate the in vitro antioxidant and anti-glycation activities of essential oils obtained from the branchlets of male and female trees and fruits of Iranian $J$. foetidissima, using five different oxidative systems.

\section{Materials and Methods}

\section{Chemicals}

All chemicals were purchased from Merck (Germany) apart from the bovine insulin were obtained from Novo Nordisk (Denmark) and AAPH from Wako (USA).

\section{Plant material}

The branchlets of male tree (BMT), branchlets of female tree (BFT) and fruits of Juniperus foetidissima Willd., Cupressaceae, were collected from Vinaq in Arasbaran (1950 m, East Azarbayejan province, northwest of Iran) in September 2001. The plant was identified by Dr. M. Assadi from the National Botanical Garden (NBG) (Tehran, Iran). Voucher specimens of the plants were deposited in the herbarium of NBG (herbarium no. 72896). The plant materials were stored at $-20{ }^{\circ} \mathrm{C}$ before use (Adams et al., 1984).

\section{Essential oils isolation}

The essential oils were obtained by steam distillation $(4 \mathrm{~h})$. The obtained essential oils were dried over anhydrous sodium sulfate and their percentages were calculated. Specific gravity of essential oils were measured using a sensitive scale (Scaitec, Germany). In addition, specific rotation (DIP-310 digital polerimeter, Electrthermal 2200, UK) and refractive index (Abbe refractometer) were determined for each oil.

\section{Gas chromatography-mass spectrometric analysis}

The GC/MS apparatus consisted of a Hewlett Packard 6890 gas chromatograph equipped with a fusedsilica column (DB-5, $30 \mathrm{~m} \times 0.25 \mathrm{~mm}$ film thickness $0.25 \mathrm{~mm}$; Agilent HP)., and interfaced with a quadruple mass spectrometric detector (HP 6890). The operating conditions were: oven temperature $60-275{ }^{\circ} \mathrm{C}$ with the rate of $4{ }^{\circ} \mathrm{C} / \mathrm{min}$; injector mode: split injection, with $\mathrm{He}$ as the carrier gas, flow rate of $2 \mathrm{~mL} / \mathrm{min}, 70 \mathrm{eV}$ ion source, $1000 \mu \mathrm{A}$ ionization current, and scan range of 30-300 $\mu$.

The oil components were identified from their retention indices (RI) obtains with reference to n-alkane series (Sigma, UK) on DB-5 column, mass spectra with those of authentic samples, composition of their mass spectra and fragmentation patters reported in literature (Adams, 2001) and computer matching with MS-data bank (Wiley Library).

A stock solution was prepared from each essential oil as follows: one hundred microliters of essential oil was added to $250 \mu \mathrm{L}$ of Tween $20(0.2 \%)$ and diluted by deionized water to a final volume of 50 $\mathrm{mL}$. The obtained mixture was shaken in ultrasonic bath (SU3 THE, Japan) for 15 min to obtain the stock emulsion (2000 ppm). Different concentrations of essential oils were prepared by transferring different volumes $(10,20$ and $30 \mu \mathrm{L}$ in the LDL oxidation assay; 1,2 and $3 \mathrm{~mL}$ in the hemoglobin and insulin glycation assays; and 40, 50 and $60 \mu \mathrm{L}$ in the linoleic acid and red blood cell hemolysis assays) of this stock emulsion to the reaction mixtures. With these volumes, final concentrations amounted to $6.25,12.5$ and $18.75 \mathrm{ppm}$ (in the LDL oxidation assay); 200, 400 and 600 ppm (in the hemoglobin and insulin glycation assays); and 180, 220 and 260 ppm (in the linoleic acid and red blood cell hemolysis assays).

\section{Susceptibility of LDL oxidation in vitro assay}

Twelve hours-fasted blood $(100 \mathrm{~mL})$ was obtained from a local blood bank from normal healthy volunteers (25-35 years, not specifically recruited for this study with the purpose of blood sampling) and mixed with $5 \mathrm{~g} / \mathrm{dL}$ EDTA solution $(3 \mathrm{~mL})$. The LDL fraction was isolated from whole plasma by ultracentrifugation (Backman L100 XP, USA) through a $\mathrm{KBr}$ discontinuous gradient (Anderson et al., 1999). 
To each ultracentrifugation tube, $9 \mathrm{~mL}$ of $1 \mathrm{mg} / \mathrm{mL}$ EDTA solution ( $\mathrm{pH}$ 7.4) was added and then mixed with plasma $/ \mathrm{KBr}$ mixture. EDTA was then removed by rapid filtration. Due to high volume of obtained LDL, it was dialyzed by special bag. Dialysis was performed in phosphate buffer saline (PBS) ( $\mathrm{pH}$ 7.4) at $4{ }^{\circ} \mathrm{C}$ for $72 \mathrm{~h}$ under nitrogen in the dark. Protein concentrations in obtained-LDL were determined by the method of Lowry (Lowry et al., 1951). LDL was oxidized using the classical copper-induced LDL autooxidation (Schinella et al., 2007). Incubations were carried out at $37^{\circ} \mathrm{C}$ for measuring the conjugated diene formation during different times up to $210 \mathrm{~min}$. In the presence and absence of each different concentration of examined oils $(6.25,12.5$ and $18.75 \mathrm{ppm})$ and vitamin $\mathrm{C}$, conjugated diene formation was determined as a measure of endogenous LDL lipid peroxidation by monitoring the increase in absorbance at $234 \mathrm{~nm}$ in a Shimadzu UV-3100 scanning spectrophotometer. All experiments were performed in triplicate. Differences in lag times ( $\mathrm{min}$ ) for $\mathrm{Cu}^{2+}$ - exposed LDL were considered as an index of oxidation (Wang et al., 2006).

\section{Hemoglobin and insulin glycation in vitro assays}

Twelve hours-fasted blood $(100 \mathrm{~mL})$ was obtained from a local blood bank from normal healthy volunteers (25-35 years, not specifically recruited for this study with the purpose of blood sampling) and mixed with $5 \mathrm{~g} / \mathrm{dL}$ EDTA solution $(3 \mathrm{~mL})$. EDTA-blood samples were centrifuged $(3000 \mathrm{x} \mathrm{g})$; the clear plasma and buffy coat layers were discarded. The red blood cells (RBCs) were washed with cold normal saline three times. Then, $0.5 \mathrm{~mL}$ of each washed-RBC was resuspended in $2 \mathrm{~mL}$ of phosphate buffer $(0.1 \mathrm{M}, \mathrm{pH} 7.4)$ and $2 \mathrm{~mL}$ of $\mathrm{CCl}_{4}$ and centrifuged at $2800 \mathrm{rpm}$ for $5 \mathrm{~min}$. The upper layers (containing hemoglobin) were transferred to new tubes and the hemoglobin concentrations were measured by Drabkin method (Drabkin et al., 1993). A dilution with final concentration of $5 \mathrm{mg} / 100 \mathrm{~mL}$ was prepared from each hemoglobin solution.

Bovine insulin (Novonordisk, Denmark) was prepared by adding phosphate buffer $0.01 \mathrm{M}(\mathrm{pH}$ 7.4) to obtain a final concentration of $100 \mathrm{Iu} / \mathrm{mL}$. Three concentrations (200, 400 and $600 \mathrm{ppm})$ of each oil were tested in this assay. These concentrations were prepared by making 1,2 and $3 \mathrm{~mL}$ of the stock essential oil emulsion $(2000 \mathrm{ppm})$ to the final volume of $10 \mathrm{~mL}$ using deionised water. All experiments were performed in triplicate. The rates of hemoglobin and insulin glycation in the presence and absence of the examined oils were measured after $48 \mathrm{~h}$ incubation at room temperature (Asgary et al., 2002).

Linoleic acid in vitro assay
One hundred fifty five microliters of linoleic acid was added to $200 \mu \mathrm{L}$ of Tween $20(0.2 \%)$ and diluted by deionized water to a final volume of $50 \mathrm{~mL}$ (emulsion $0.01 \mathrm{M}$ ). The obtained mixture was shaken in an ultrasonic bath for 15 min (Farag et al., 1989). The obtained linoleic acid emulsion was neutralized by $\mathrm{KOH} 1 \mathrm{~N}(\mathrm{pH} 7)$ and diluted by phosphate buffer (pH 7) to a final volume of $75 \mathrm{~mL}$ (Valenzuela et al., 1986). This emulsion was used to monitor linoleic acid peroxidation in the presence and in the absence of three different concentrations of each essential oil $(480,600$ and $7200 \mathrm{ppm})$. Oxidation was initiated by addition of a FeSO4 solution (final concentration, $500 \mu \mathrm{M}$ ) to a mixture of $1.5 \mathrm{~mL}$ of linoleic acid emulsion and 0.5 $\mathrm{mL}$ of $\mathrm{K}_{2} \mathrm{HPO}_{4}$. The control was treated with the same volume of the vehicle solution of the solvent; $\mathrm{K}_{2} \mathrm{HPO}_{4}$. Incubation was performed at $37^{\circ} \mathrm{C}$ for $4 \mathrm{~h}$. Linoleic acid peroxidation was monitored by absorbance changes (at $233 \mathrm{~nm}$ ) in a spectrophotometer. The percentage increased of conjugated diene between 0 and $4 \mathrm{~h}$ was determined every one hour. All assays were performed in triplicate. The inhibitory effect of each oil against conjugated diene production was calculated for each hour of the test using the following formula:

$$
\% \text { Inhibition }=\left(1-\frac{\text { Sample absorption }}{\text { Negative control absorption }}\right) \times 100
$$

\section{Red blood cells hemolysis in vitro assay}

RBC were isolated by centrifugation of heparinized blood obtained from healthy donors and washed three times by normal saline solution. WashedRBC was suspended to $10 \%$ hematocrit in phosphatebuffered saline. 2,2'-Azobis dihydrochloride (AAPH) was used to induce RBC oxidation. The assay relies on ability of the hydrophilic radical generator AAPH to generate peroxyl radicals, thereby oxidizing $\mathrm{RBC}$ and measuring the extent of $\mathrm{RBC}$ hemolysis by spectroscopic assay (Ljubuncic et al., 2006). Aliquots $(1 \mathrm{~mL})$ of diluted RBC were incubated with $1 \mathrm{~mL}$ of freshly prepared $25 \mathrm{mM} \mathrm{AAPH}$ in the absence (negative control) and presence of different concentrations of $J$. foetidissima essential oils $(180,220$ and $260 \mathrm{ppm})$ at $37^{\circ} \mathrm{C}$ for $2 \mathrm{~h}$. After $10 \mathrm{~min}$ centrifugation $(3000 \mathrm{x} \mathrm{g})$, the absorbance reading of supernatant was evaluated at $540 \mathrm{~nm}$. Each assay was performed for six times. The percentage of inhibitory effect of each sample against $\mathrm{RBC}$ hemolysis was calculated using the following formula:

$$
\% \text { Inhibition }=\left(1-\frac{\text { Sample absorption }}{\text { Negative control absorption }}\right) \times 100
$$




\section{Statistical analyses}

Values were expressed as mean $\pm \mathrm{SD}$. Betweengroup comparisons were made using one-way or two-way analysis of variance (ANOVA). A two-sided $p$-value of $<0.05$ was considered to be significant.

\section{Results}

\section{Phytochemical analysis}

The obtained essential oils of the BMT, BFT and fruits of $J$. foetidissima were clear and colorless with a total yield of $0.87 \%$ (BMT oil), $0.75 \%$ (BFT oil) and $0.45 \%$ (fruit oil). Specific gravity, refractive index and specific rotation of the obtained essential oils were $0.86,1.47$ and +79.6 (BMT oil), 0.84, 1.47 and +90.4 (BFT oil), and 0.87, 1.47 and +77.6 (fruit oil), respectively.

Analysis of $J$. foetidissima oils led to the identification of 13,13 and 17 compounds amounting to $92.54 \%, 62.21 \%$ and $96.84 \%$ of the BMT, BFT and fruit essential oils, respectively. Monoterpene hydrocarbons were the most frequent class of compounds in all three oils. Limonene was the major constituent of the BMT oil (36.30\%), whereas in the BFT and fruit oils, sabinene was the most abundant compound (34.29 and $27.10 \%$, respectively, Table 1 ).

\section{LDL oxidation}

The antioxidant capacity of $J$. foetidissima volatile oils against copper-mediated LDL-oxidation was assessed using three different concentrations of each oil $(6.25,12.5$ and $18.75 \mathrm{ppm})$. Vitamin $\mathrm{C}$ as a positive control could totally inhibit LDL oxidation and remarkably prolonged the lag phase of the reaction which was used as a sensitive index of the antioxidant effects [lag phase duration $15 \mathrm{~min}$ (negative control) and 165 min (vitamin C sample)]. The results demonstrated that all three evaluated oils possessed slight antioxidant activities in this system. These antioxidant effects were found to be increased at higher concentrations. For the BMT oil, duration of lag phase was found to be $35 \mathrm{~min}$ in the negative control and 45, 45 and $50 \mathrm{~min}$ in the $6.25,12.5$ and $18.75 \mathrm{ppm}$ concentrations of essential oil, respectively. For the BFT oil, duration of lag phase was increased from $65 \mathrm{~min}$ in the negative control to 75 min in the $18.75 \mathrm{ppm}$ concentration of oil. In contrast, duration of lag phase was shorter in the $6.25 \mathrm{ppm}$ concentration (55 $\mathrm{min}$ ) and unchanged in the $12.5 \mathrm{ppm}$ concentration. As for the fruit oil, duration of lag phase was increased from $40 \mathrm{~min}$ in the negative control to 45 min (in both 6.25 and 12.5 ppm concentrations) and 50 $\min$ (in $18.75 \mathrm{ppm}$ concentration).
Table 1. Chemical composition (\%) of the branchlet and fruit oils of Juniperus foetidissima.

\begin{tabular}{|c|c|c|c|c|}
\hline \multirow{2}{*}{ Component } & \multirow{2}{*}{$\mathrm{RRI}^{\mathrm{a}}$} & \multicolumn{3}{|c|}{ RA $(\%)^{b}$} \\
\hline & & BMT oil & BFT oil & Fruit oil \\
\hline$\alpha$-Thujene & 935 & 1.2 & 2.1 & 1.6 \\
\hline$\alpha$-Pinene & 942 & $17.4^{\mathrm{c}}$ & 8.7 & $19.8^{c}$ \\
\hline Sabinene & 985 & 19.1 & 34.3 & 27.1 \\
\hline$\beta$-Pinene & 990 & 4.9 & 2.4 & 5.9 \\
\hline$\delta$-2-Carene & 1012 & - & 1.5 & 3.2 \\
\hline$\alpha$-Terpinene & 1022 & 0.4 & 1.8 & $0.8^{\mathrm{c}}$ \\
\hline Limonene & 1050 & $36.3^{\mathrm{c}}$ & $5.8^{\mathrm{c}}$ & 25.5 \\
\hline$\gamma$-Terpinene & 1065 & $0.9^{c}$ & 2.3 & 1.5 \\
\hline Isoterpinolene & 1088 & $0.5^{\mathrm{c}}$ & 0.6 & 2.4 \\
\hline$E$-Thujone & 1130 & 9.0 & 0.7 & 1.2 \\
\hline Terpinen-4-ol & 1158 & $0.6^{\mathrm{c}}$ & 0.4 & 1.6 \\
\hline$\alpha$-Cubebene & 1350 & - & - & 0.8 \\
\hline$E$-Caryophyllene & 1435 & trace & - & 0.8 \\
\hline$\alpha$-Humulene & 1450 & - & - & 1.2 \\
\hline Germacrene D & 1492 & - & - & 2.5 \\
\hline$\gamma$-Cadinene & 1535 & 0.2 & 1.3 & 0.8 \\
\hline Cedrol & 1630 & 2.1 & 0.2 & 0.1 \\
\hline $\begin{array}{l}\text { Monoterpene } \\
\text { hydrocarbons }\end{array}$ & & 80.7 & 59.5 & 87.8 \\
\hline $\begin{array}{l}\text { Oxygenated } \\
\text { Monoterpenes }\end{array}$ & & 9.6 & 1.1 & 2.8 \\
\hline $\begin{array}{l}\text { Sesquiterpene } \\
\text { hydrocarbons }\end{array}$ & & 0.2 & 1.3 & 6.1 \\
\hline $\begin{array}{l}\text { Oxygenated } \\
\text { sesquiterpenes }\end{array}$ & & 2.1 & 0.2 & 0.1 \\
\hline Total identified & & 92.6 & 62.1 & 96.8 \\
\hline
\end{tabular}

BMT: branchlets of male tree; BFT: branchlets of female tree. ${ }^{\text {aRRI: }}$ Relative retention indices as determined on a CP-SIL 8 CB column using the homologous series of $n$-alkanes. ${ }^{b} \mathrm{RA}$ : Relative area (peak area relative to total peak area). 'Structure was confirmed by GC-FTIR.

\section{Hemoglobin glycation}

All three tested essential oils showed degrees of anti-glycation activity. The most marked effects were observed from fruit oils, which were greater than those of branchlet oils at all tested concentrations. Inhibitory activities of three assessed oils were not regularly augmented by increasing concentrations. The highest anti-glycation effect of oils was observed from fruit oil at $200 \mathrm{ppm}(94.7 \%)$, while the peak activities for the oils of BMT and BFT were at 400 ppm concentration being $45.1 \%$ and $62.4 \%$, respectively. For all oils the lowest activity was observed at $600 \mathrm{ppm}$ concentration (Table 2). There were significant differences among different concentrations of each oil $(p<0.001)$.

\section{Insulin glycation}

All three tested oils possessed promising 
inhibitory activity against insulin glycation. The inhibition rates were generally higher than those observed against hemoglobin glycation. The same as hemoglobin system, no regular dose-dependent inhibition was found by increasing concentrations. The highest activity was observed from fruit oil at 600 ppm concentration (100\%), while the peak activities for the BMT and BFT oils were at 200 (96.9\%) and $600(96.9 \%)$ ppm concentrations, respectively. For all oils the lowest activity was observed at $400 \mathrm{ppm}$ concentration (Figure 1). No significant difference was observed in the insulin glycation inhibition rate among different concentrations of each oil $(p>0.05)$.

Table 2. Inhibitory effects of $J$. foetidissima essential oils against hemoglobin glycation.

\begin{tabular}{lccc}
\hline & $200 \mathrm{ppm}$ & $400 \mathrm{ppm}$ & $600 \mathrm{ppm}$ \\
\hline BMT oil & $43.33 \pm 0.80$ & $45.11 \pm 0.63$ & $10.00 \pm 0.63$ \\
BFT oil & $25.55 \pm 0.22$ & $62.44 \pm 0.50$ & $-9.11 \pm 0.31$ \\
Fruit oil & $94.66 \pm 0.31$ & $87.11 \pm 0.22$ & $74.00 \pm 0.31$ \\
\hline BMT: branchlets of male tree; BFT: branchlets of female tree.
\end{tabular}

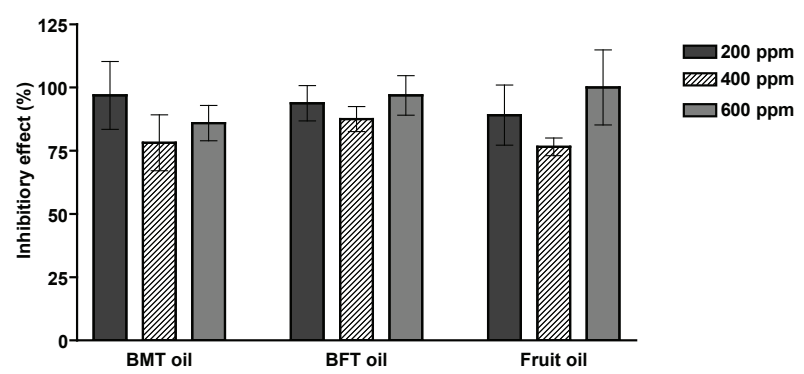

Figure 1. Inhibitory effects of $J$. foetidissima essential oils against insulin glycation. BMT: branchlets of male tree; BFT: branchlets of female tree.

\section{Linoleic acid peroxidation}

All of the assessed oils demonstrated antioxidant capacity against linoleic acid peroxidation, though in varying degrees. Overall, the fruit oil was found to be of weaker activity compared to branchlet oils. The highest antioxidant activities of BMT and BFT oils were frequently observed after $3 \mathrm{~h}$ of incubation (Figures 2-4). In two-way ANOVA, antioxidant activity was found to be significantly affected by essential oil concentration ( $p=0.002,0.045$ and 0.001 for BMT, BFT and fruit oil, respectively) and duration of incubation $(p=0.006, \quad p<0.001$ and $p<0.001)$. A significant interaction between essential oil concentration and duration of incubation was also observed $(p<0.001$, $p=0.003$ and $p<0.001)$.

\section{Peroxyl radical mediated $R B C$ hemolysis}

Based on the results of the in vitro RBS hemolysis assay, it appears that only the fruit oil possesses anti-hemolytic effects. This notion is based on the observed inhibition of peroxyl radical mediated RBC hemolysis by fruit oil at all three evaluated concentrations. In contrast, volatile oils from BMT and BFT were only found to exert anti-hemolytic effects at a single concentration: 220 and 180 ppm for BMT and BFT oil, respectively. Otherwise, these latter oils increased the $\mathrm{RBC}$ hemolysis rate. The effects of examined oils on RBC hemolysis were not found to follow a regular dose dependence pattern (Figure 5). In one-way ANOVA, there was a significant concentration effect in the anti-hemolytic effects for BFT $(p<0.001)$ and BFT $(p=0.011)$ oils, but not fruit oil $(p>0.05)$.

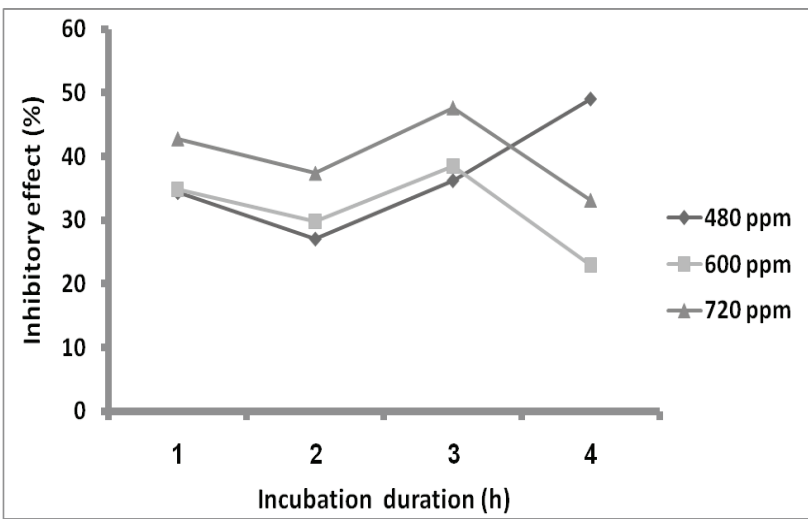

Figure 2. Inhibitory effects of $J$. foetidissima BMT oil against linoleic acid peroxidation.

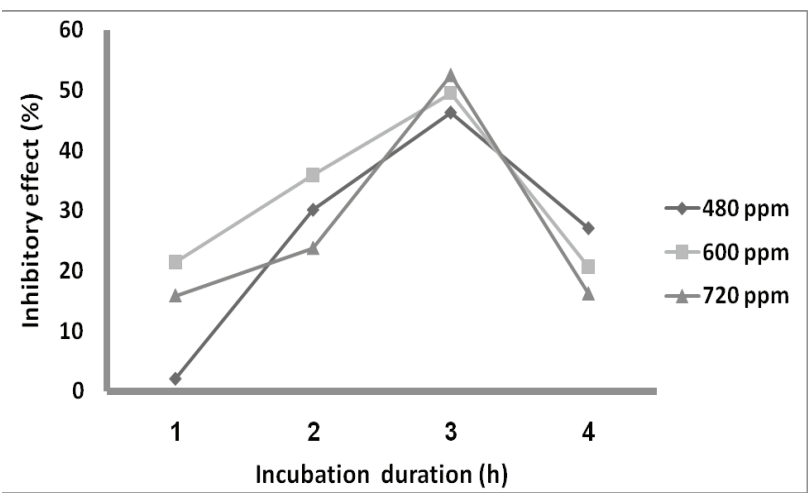

Figure 3. Inhibitory effects of $J$. foetidissima BFT oil against linoleic acid peroxidation.

\section{Discussion}

Overall, the findings of the present study implied that essential oils obtained from fruits, BMT and BFT of $J$. foetidissima possess antioxidant properties in all five oxidation systems that were employed, apart from pro-oxidant effects of branchlet oils in the erythrocyte hemolysis assay. The most promising 


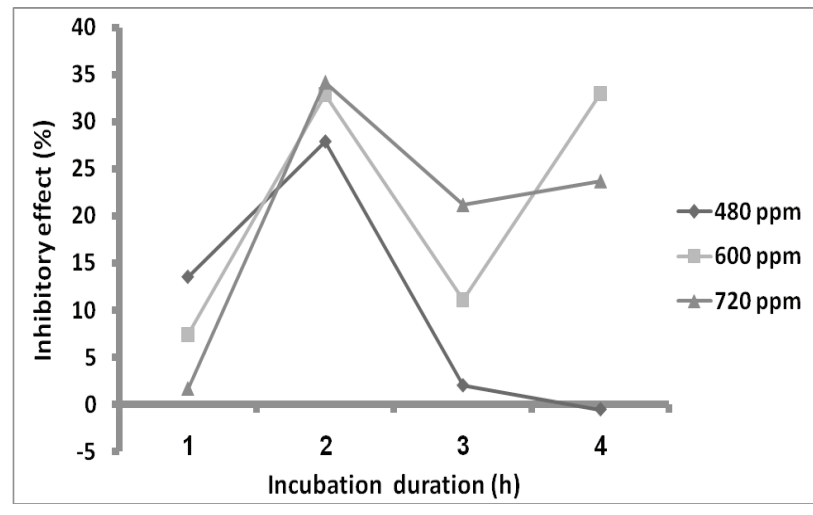

Figure 4. Inhibitory effects of $J$. foetidissima fruit oil against linoleic acid peroxidation.

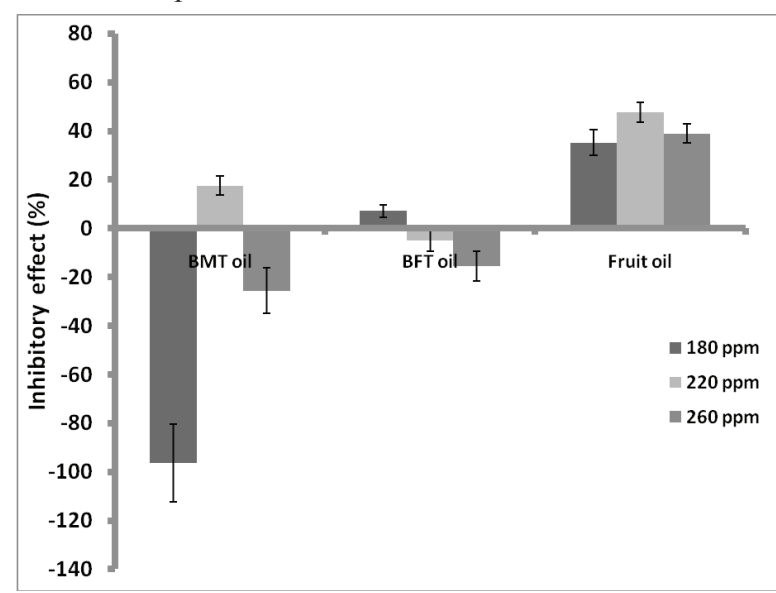

Figure 5. Inhibitory effects of $J$. foetidissima oils against peroxyl radical mediated RBC hemolysis. BMT: branchlets of male tree; BFT: branchlets of female tree.

antioxidant effects of $J$. foetidissima oils were those observed against hemoglobin and, in particular, insulin glycation. Glycation of proteins is an irreversible nonenzymatic reaction between reducing carbohydrates and free amino groups of proteins (Forbes et al., 2005). The products of such a reaction, called AGE, are highly reactive molecules associated with cardiovascular disease and diabetic complications (Kawamura et al., 1994; Napoli et al., 1997; Jakus et al., 1998; Liguori et al., 2001; Dickinson et al., 2002; KrajcovicováKudlácková et al., 2002; Peppa \& Raptis, 2008). There is evidence indicating the role of free radicals as predisposing factors for protein glycation as well as the impact of AGE in the amplification of oxidative stress (Dickinson et al., 2002). An effective strategy to halt this vicious cycle is to use antioxidants. During recent decades, there has been increasing interest for finding effective antioxidants from natural sources and, most importantly, plant origin. In this context, essential oils represent a promising option as there are numerous reports confirming their antioxidant effects (Chemat et al., 2007; Souza et al., 2007). For instance volatile oils of sage and rosemary have been proposed as effective alternatives for butylated hydroxy toluene (BHT), a widely used synthetic antioxidants with known side effects (Wichi, 1986; Estevez et al., 2007). However, there have been relatively few reports on the plants of Cupressaceae family.

In a previous report, some antioxidant activities of $J$. foetidissima fruit and branchlet oils were reported using DPPH free radical scavenging and deoxyribose degradation assays (Emami et al., 2009). In another survey on the antioxidant activities of Iranian conifers, methanolic extracts from fruits, BMT and BFT of $J$. foetidissima were found to possess activity in the ferric thiocyanate and thiobarbituric acid (TBA) assays. The antioxidant effects of $J$. foetidissima extracts in the mentioned assays were more than $80 \%$ apart from a weaker effect from MBT extract in the TBA method (Emami et al., 2007). The results of the current study further confirm antioxidant capacity of this plant by using five other in vitro oxidative systems. These antioxidant effects could be due to the presence of terpenoid compounds as leading constituents of essential oils (Grassmann, 2005). In the present study, monoterpenes were predominant over other classes of compounds in all three assessed oils. Thus far, several investigations have indicated the antioxidant capacity of monoterpenes. Of note, limonene and sabinene which were found as the major components of J. foetidissima oils have been separately shown to possess antioxidant effects (Emami et al., 2009; Roberto et al., 2010). Nevertheless, it appears that the overall antioxidant activity of essential oils is usually the consequence of synergistic interactions among a number of active constituents rather than the presence of a single agent.

Phytochemical analysis of the J. foetidissima fruit and branchlet oils revealed that sabinene, limonene, $\alpha$-pinene and $\beta$-pinene were the major constituents of all three oils. This finding is consistent with previous reports on the essential oils from the same parts of this plant in Iran (Emami et al., 2007; Emami et al., 2009). In the first study (Emami et al., 2009), Emami and colleagues investigated the oils of $J$. foetidissima from Iran, and reported 34, 31 and 33 identified compounds accounting for $98.7 \%, 98.9 \%$ and $97.2 \%$ of the oils from male BMT, BFT and fruits of the plant, respectively. Limonene (56.4$27.73 \%$ ), sabinene (27.57-16.20\%), $\alpha$-pinene, (14.53-9.67 $\%)$ and $\beta$-thujone turned out to be the main components of the investigated oils. In a later report by Asili et al. (Asili et al., 2010), 39, 39 and 36 compounds representing 95.7, 98.6 and $97.5 \%$ of the total essential oils from BMT, BFT and fruits of Iranian $J$. foetidissima were identified. In consistence with the current and previous study, sabinene (16.8-37.1\%), $\alpha$-pinene, (18.6-29.9\%) and limonene (11.8$20.9 \%$ ) were the major components of the oils. There have been also reports on the chemical composition of essential 
oils obtained from different parts of J. foetidissima from Turkey. Based on this latter study, $\beta$-thujone (leaf, seed and seedless cone berry oils), cedrol (leaf oil), sabinene (cone berry, seed and seedless cone berry oils), abietal (seed and seedless cone berry oils) and $\alpha$-pinene (branch oil) were found as the main components of the assessed oils (Tunalier et al., 2002). In another survey on the chemical compositions of essential oils from heartwood of the root and stem of this plant from Turkey, the main components were reported to be cedrol (13-15\%), widdrol (9-12\%), 8,14-cedranoxide (7-8\%), 14-hydroxy-(E)-caryophyllene (5-9\%), cis-thujopsene (10-11\%) and $\alpha$-cedrene (6-8\%) (Tunalier et al., 2004).

The compositional differences in the aforementioned essential oils could be attributed to several biological (e.g. part of the source plant which is being extracted, age and growth stage) and environmental (e.g. climatic/geographical conditions and soil characteristics) factors as well as extraction methods that were applied (Masotti et al., 2003; Angioni et al., 2006).

To sum up, the present findings implied that essential oils obtained from branchlets and fruits of J. foetidissima possess antioxidant and anti-glycation activities. These anti-glycation effects may be of clinical significance especially for the prevention of diabetic complications. However, future investigations are required to clarify whether these in vitro findings could be extended to in vivo situations as well as the potential inhibitory effects of these oils against other important proteins involved in the pathogenesis of diabetic complications.

\section{Acknowledgements}

The authors would like to thank the authorities of the Mashhad University of Medical Sciences research council as well as authorities of the Isfahan University of Medical Sciences for their respective supports. The authors also wish to express their sincerest gratitude to Mrs. A. Jamshidi for her kind helps.

\section{References}

Adams RP, Zanoni TA, Hogge L 1984. The volatile leaf oils of Juniperus flaccida var. flaccida and var. poblana. J Nat Prod 47: 1064-1065.

Adams RP 2001. Identification of essential oils components by gas chromatography/quadrapole mass spectroscopy. Carol Stream: Allured Publishing Corp.

Anderson JW, Gowri MS, Turner J, Nichols L, Diwadkar VA, Chow CK, Oeltgen PR 1999. Antioxidant supplementation effects on low-density lipoprotein oxidation for individuals with type 2 diabetes mellitus. $J$ Am Coll Nutr 18: 451-461.

Angioni A, Barra A, Coroneo V, Dessi S, Cabras P 2006. Chemical composition, seasonal variability, and antifungal activity of Lavandula stoechas L. ssp. stoechas essential oils from stem/leaves and flowers. J Agric Food Chem 54: 4364-4370.

Asgary S, Naderi GA, Sarraf-Zadegan N, Vakili R 2002. The inhibitory effects of pure flavonoids on in vitro protein glycosylation. J Herbal Pharmacother 2: 47-55.

Asili J, Emami SA, Rahimizadeh M, Fazly-Bazzaz BS, Hassanzadeh MK 2010. Chemical and antimicrobial studies of Juniperus sabina L. and Juniperus foetidissima Willd. essential oils. J Essent Oil Bear Pl 13: 25-36.

Assadi M 1998. Cupressaceae. In Assadi M, Khatamsaz M, Maassoumi AA, Mozaffarian V (eds) Flora of Iran. vol. 21. Tehran: Research Institute of Forests and Rangelands, p. 27-28.

Balaban M, Atik C, Ucar G 2003. Fungal growth inhibition by wood extracts from Juniperus foetidissima and $J$. oxycedrus. Holz als Roh - und Werkstoff 61: 231-232.

Beal MF, Howell N, Bodis-Wollner I 1997. Mitochondria and free radicals in neurodegenerative diseases. New York: Wiley-Liss.

Chemat F, AbertVian M, Dangles O 2007. Essential oils as antioxidants. Int $J$ Essent Oil Ther 1: 4-15.

Chrissobolis S, Faraci FM 2008. The role of oxidative stress and NADPH oxidase in cerebrovascular disease. Trends $\mathrm{Mol}$ Med 14: 495-502.

Dickinson PJ, Carrington AL, Frost GS, Boulton AJM 2002. Neurovascular disease, antioxidants and glycation in diabetes. Diabetes Metab Res 18: 260-272.

Drabkin HJ, Helk B, RajBhandary UL 1993. The role of nucleotides conserved in eukaryotic initiator methionine tRNAs in initiation of protein synthesis. $J$ Biol Chem 268: 25221-25228.

Emami SA, Asili J, Mohagheghi Z, Hassanzadeh MK 2007. Antioxidant activity of leaves and fruits of Iranian conifers. Evid Based Complement Alternat Med 4: 313319.

Emami SA, Shahidi NH, Hassanzadeh-Khayyat M 2009. Antioxidant activity of the essential oils of different parts of Juniperus sabina L. and Juniperus foetidissima Willd (Cupressaceae). Int J Essent Oil Ther 3: 163-170.

Esterbauer H, Schaur RJ, Zollner H 1991. Chemistry and biochemistry of 4-hydroxynonenal, malonaldehyde and related aldehydes. Free Radic Biol Med 11: 81-128.

Esterbauer H, Gebicki J, Puhl H, Jurgens G 1992. The role of lipid peroxidation and antioxidants in oxidative modification of LDL. Free Radic Biol Med 13: 341-390.

Estevez M, Ramírez R, Ventanas S, Cava R 2007. Sage and rosemary essential oils versus BHT for the inhibition of lipid oxidative reactions in liver pate. LWT - Food Sci Technol 40: 58-65.

Farag RS, Badei AZMA, Hewedi FM, El-Baroty GSA 1989. Antioxidant activity of some spice essential oils on linoleic acid oxidation in aqueous media. $\mathrm{J} \mathrm{Am} \mathrm{Oil} \mathrm{Chem}$ Soc 66: 792-799.

Forbes JM, Soldatos G, Thomas MC 2005. Below the radar: advanced glycation end products that detour "around the side". Is HbAlc not an accurate enough predictor of long term progression and glycaemic control in diabetes? Clin Biochem Rev 26: 123-134.

Giacco F, Brownlee M 2010. Oxidative stress and diabetic complications. Circ Res 107: 1058-1070.

Grassmann J 2005. Terpenoids as plant antioxidants. Vitam Horm 


\section{2: $505-535$}

Green DR, Reed JC 1998. Mitochondria and apoptosis. Science 281: 1309-1312.

Jakus V, Cársky J, Hrnciarová M 1998. Importance of advanced glycation end products-AGE products. Bratisl Lek Listy 99: 368-375.

Kawamura M, Heinecke JW, Chait A 1994. Pathophysiological concentrations of glucose promote oxidative modification of low density lipoprotein by a superoxide-dependent pathway. J Clin Invest 94: 771-778.

Krajcovicová-Kudlácková M, Sebeková K, Schinzel R, Klvanová J 2002. Advanced glycation end products and nutrition. Physiol Res 51: 313-316.

Lakshmi SVV, Padmaja G, Kuppusamy P, Kutala VK 2009. Oxidative stress in cardiovascular disease. Indian $J$ Biochem Biophys 46: 421-440.

Ljubuncic P, Dakwar S, Portnaya I, Cogan U, Azaizeh H, Bomzon A 2006. Aqueous extracts of Teucrium polium possess remarkable antioxidant activity in vitro. Evid Based Complement Alternat Med 3: 329-338.

Nigam S, Schewe T 2000. Phospholipase A2s and lipid peroxidation. Biochim Biophys Acta 1488: 167-181.

Liguori A, Abete P, Hayden JM, Cacciatore F, Rengo F, Ambrosio G, Bonaduce D, Condorelli M, Reaven PD, Napoli C 2001. Effect of glycaemic control and age on low-density lipoprotein susceptibility to oxidation in diabetes mellitus type 1. Eur Heart J 22: 2075-2084.

Lowry OH, Rosebrough NJ, Farr AL, Randall RJ 1951. Protein measurement with the Folin phenol reagent. J Biol Chem 193: 265-275.

Masotti V, Juteau F, Bessiere JM, Viano J 2003. Seasonal and phenological variations of the essential oil from the narrow endemic species Artemisia molinieri and its biological activities. J Agric Food Chem 51: 7115-7121.

Napoli C, Triggiani M, Palumbo G, Condorelli M, Chiariello M, Ambrosio G 1997. Glycosylation enhances oxidation and decreases acetylhydrolase activity of human low density lipoprotein. Basic Res Cardiol 92: 96-105.

Peppa M, Raptis SA 2008. Advanced glycation end products and cardiovascular disease. Curr Diabetes Rev 4: 92-100.

Riedl H 1968. Cupressaceae. vol. 50. Graz: Akademische Drucku. Verlagsanstalt, p. 7.

Roberto D, Micucci P, Sebastian T, Graciela F, Anesini C 2010. Antioxidant activity of limonene on normal murine lymphocytes: relation to $\mathrm{H}_{2} \mathrm{O}_{2}$ modulation and cell proliferation. Basic Clin Pharmacol Toxicol 106: 38-44.

Sabeti H 1975. Forests, trees and shrubs of Iran. Tehran:
Ministry of Information and Tourism Press, p. 420421.

Sadeghi-aliabadi H, Emami A, Saidi M, Sadeghi B, Jafarian A 2009. Evaluation of in vitro cytotoxic effects of Juniperus foetidissima and Juniperus sabina extracts against a panel of cancer cells. Iranian J Pharm Res 8: 281-286.

Schinella GR, Tournier HA, Manez S, de Buschiazzo PM, del Carmen Recio M, Rios JL 2007. Tiliroside and gnaphaliin inhibit human low density lipoprotein oxidation. Fitoterapia 78: 1-6.

Souza TJT, Apel MA, Bordignon S, Matzenbacher NI, Zuanazzi JAS, Henriques AT 2007. Chemical composition and antioxidant activity of the volatile oil from Eupatorium potystachyum DC. Rev Bras Farmacogn 17: 368-372.

Tunalier Z, Kirimer N, Baser KHC 2002. The composition of essential oils from various parts of Juniperus foetidissima. Chem Nat Comp 38: 43-47.

Tunalier Z, Kirimer N, Baser KHC 2004. A potential new source of Cedarwood oil: Juniperus foetidissima willd. J Essent Oil Res 16: 233-235.

Valenzuela A, Guerra R, Videla LA 1986. Antioxidant properties of the flavonoids silybin and (+)-cyanidanol-3: Comparison with butylated hydroxyanisole and butylated hydroxytoluene. Planta Med 6: 438-440.

Wang R, Wei W, Wang L, Liu R, Yi D, Du L, 2006. Constituents of the flowers of Punica granatum. Fitoterapia 77: 534537.

Wautier JL, Guillausseau PJ 2001. Advanced glycation end products, their receptors and diabetic angiopathy. Diabete Metab 27: 535-542.

Wichi HC 1986. Safety evaluation of butylated hydroxytoluene (BHT) in the liver, lung and gastrointestinal tract. Food Chem Toxicol 24: 1127-1130.

Ylä-Herttuala S, Pakkanen T, Leppänen P, Häkkinen T 2000. Oxidized low-density lipoproteins and atherosclerosis. $J$ Clin Basic Cardiol 3: 87-88.

\section{*Correspondence}

Seyed Ahmad Emami

Department of Pharmacognosy, School of Pharmacy, Mashhad University of Medical Sciences Mashhad, Iran

emamia@mums.ac.ir

Tel: +98 5118823255

Fax: +98 5118823251 